\title{
Temporal trends and risks factors for antimicrobial resistant Enterobacteriaceae urinary isolates from outpatients in Guadeloupe
}

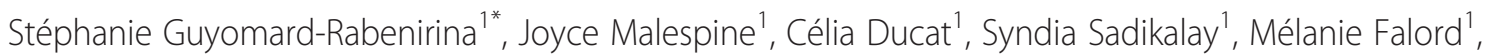
Dorothée Harrois², Vincent Richard ${ }^{5}$, Charles Dozois ${ }^{6}$, The Laboratory working group, Sébastien Breurec ${ }^{1,3,4}$ and Antoine Talarmin ${ }^{1}$

\begin{abstract}
Background: Urinary tract infections are bacterial infections most commonly encountered in the community. The resistance rate of uropathogens to commonly prescribed antibiotics has increased worldwide but there are no published data concerning the resistance of strains isolated from community-acquired UTI in Guadeloupe. To assess the susceptibility patterns of Enterobacteriaceae strains isolated from outpatients in Guadeloupe we conducted a prospective study from December 2012 to May 2014 among outpatients consulting at private and public laboratories for urine analysis. Risk factors for $E$. coli resistance to amoxicillin, third-generation cephalosporin, and ciprofloxacin were also determined. To study the trends of $E$. coli resistance rates over the past 10 years, data on the susceptibility patterns of E. coli from 2003 to 2014 were also collected from three major laboratories for a retrospective study.

Results: During the prospective study, we isolated 1293 bacterial strains from the urine of outpatients presenting for urine analysis. The most commonly isolated bacteria were E. coli (57 \%) and Klebsiella pneumoniae (15.5\%). Thirty seven per cent of the E. coli strains were resistant to amoxicillin. Resistance rates to third generation cephalosporin were low for E. coli and other Enterobacteriaceae (3.1 and $12.2 \%$ respectively) and mostly due to the presence of an Extended Spectrum Beta-lactamase. Resistance to cotrimoxazole and ciprofloxacin was moderate (17.8 and $15.6 \%$ respectively). However, the resistance rate of E. coli to ciprofloxacin has significantly increased during the last 10 years. Risk factors were consistent with previously reported data, especially for the increasing ciprofloxacin resistance with age.
\end{abstract}

Conclusion: General practitioners in Guadeloupe need to be better informed to favor the prescription of fosfomycin-trometamol to reduce the risk of resistance to fluoroquinolones.

Keywords: Urinary tract infections, Enterobacteriaceae, Antibiotic resistance

\footnotetext{
* Correspondence: sguyomard@pasteur-guadeloupe.fr

'Unité Environnement Santé, Institut Pasteur de Guadeloupe, Les Abymes,

Guadeloupe, France

Full list of author information is available at the end of the article
} 


\section{Background}

Urinary tract infections (UTI) are bacterial infections most commonly encountered in the community, regardless of age. UTIs are usually benign and the infection (cystitis, prostatitis, urethritis) is limited to the lower urinary tract requires a simple antibiotic treatment. However, recurrences are common and may evolve into an upper UTI (pyelonephritis) requiring a heavier antibiotic treatment and more extensive management [1].

Enterobacteriaceae, especially Escherichia coli, are the most prevalent uropathogens in patients with UTI, both in the community and hospitals [2]. In most cases, the treatment of uncomplicated UTIs is empirical. The French Language Infectious Disease Society (SPFIL) recommends using a single dose of fosfomycin-trometamol in combination for the first line treatment of UTI and pivmecillinam for second line therapy. Beta-lactams, quinolones or cotrimoxazole should be administered after susceptibility testing since strains resistant to these antibiotics are frequently isolated. Indeed, multi drug resistant strains are emerging, especially strains harboring Extended Spectrum Betalactamases (ESBL). ESBL enzymes can hydrolyze almost all beta-lactams (except for carbapenems and cephamycins) and their genes are often closely linked to other genes that confer resistance to several other classes of antibiotics. During the past decade, CTX-M enzymes have gradually replaced the classical TEM and SHV-type ESBLs in many countries. The rapid international spread of CTX-M-15 has been associated with the global dissemination of particular $E$. coli clones, such as sequence type 131 [3].

The resistance rate of uropathogens to commonly prescribed antibiotics has increased worldwide: resistance to quinolones and trimethoprim increased in Europe between the ECO-SENS I (1999-2000) and ECO-SENS II (2007-2008) studies and in Africa (Senegal, Central African Republic) between 2003 and 2006, reducing therapeutic options [4-7].

Guadeloupe, a French overseas territory located in the Caribbean, is a very high resource country according to the Human Development Index in 2013. There are no published data concerning the resistance of strains isolated from community-onset UTI in Guadeloupe and data from the Caribbean more generally are rare. We, therefore, conducted a prospective study, from December 2012 to May 2014, to assess the susceptibility patterns of Enterobacteriaceae strains isolated from outpatients and to determine the risk factors for UTIs due to Enterobacteriaceae resistant to commonly used antimicrobial agents. We also studied the genetic basis for the antibiotic resistance of ESBL-producing Enterobacteriaceae. Finally, to determine the recent trends of resistance to antibiotics, we conducted a retrospective study on the antibiotic resistance of $E$. coli isolated from outpatients during the last 10 years.

\section{Methods \\ Patients}

We collected 1293 bacterial strains isolated from the urine of outpatients presenting for a urine analysis from 13 of the 23 private Guadeloupian laboratories and the laboratory of the Hospital of Basse-Terre between December 2012 and May 2014. All strains responsible for lower and upper UTI and bacteriuria according to SPFIL criteria (pyuria $\geq 10^{4}$ leucocyte $/ \mathrm{mL}$ and bacteriuria $\geq 10^{3}$ for $E$. coli or $S$. saprophyticus and $\geq 10^{4}$ for other species) [8] were included in the study. Only one specimen was collected from each patient. The leucocyte count, isolation, identification and antibiotic susceptibility testing of bacteria were conducted by all laboratories according to their routine diagnostic procedures. All Enterobacteriaceae strains were sent to the Pasteur Institute of Guadeloupe for complete antibiotic susceptibility testing.

The study protocols were approved by the French Advisory Committee on Information Processing in Material Research in the Field of Health (CCTIRS 12-220). Written informed consent to participate in the study was obtained from all patients.

\section{Antibiotic susceptibility testing of Enterobacteriaceae at the Pasteur Institute of Guadeloupe}

We assessed the susceptibility to the following antibiotics by the disk diffusion technique on Mueller-Hinton $\operatorname{agar}(\mathrm{MH})$ as recommended by the Antibiogram Committee of the French Microbiology Society (ACFMS) [9]: amoxicillin $(10 \mu \mathrm{g})$, amoxicillin-clavulanic acid $(20 \mu \mathrm{g} /$ $10 \mu \mathrm{g})$, ticarcillin $(75 \mu \mathrm{g})$, cephalothin $(30 \mu \mathrm{g})$, cefotaxime $(30 \mu \mathrm{g})$, ceftazidime $(30 \mu \mathrm{g})$, cefoxitin $(30 \mu \mathrm{g})$, aztreonam $(30 \mu \mathrm{g})$, imipenem $(10 \mu \mathrm{g})$ gentamicin $(15 \mu \mathrm{g})$, amikacin $(30 \mu \mathrm{g})$, trimethoprim/sulfamethoxazole $(1,25 /$ 23,75 $\mu \mathrm{g})$, nalidixic acid $(30 \mu \mathrm{g})$, ciprofloxacin $(5 \mu \mathrm{g})$, fosfomycin $(50 \mu \mathrm{g})$, nitrofurantoin $(300 \mu \mathrm{g})$ and tetracycline (30 UI).. Inhibition growth diameters were measured using the Adagio automated system (Bio-Rad, France). Intermediate and resistant strains were grouped together and classified as resistant strains. Extended spectrum beta-lactamases were detected for strains with reduced inhibition growth diameters around cefotaxime, ceftazidime or aztreonam by the combined disk method with the following combinations: cefotaxime $(30 \mu \mathrm{g})$ and ceftazidime $(30 \mu \mathrm{g})$; cefotaxime $(30 \mu \mathrm{g})$ and clavulanate $(10 \mu \mathrm{g})$; and ceftazidime $(30 \mu \mathrm{g})$ and clavulanate $(10 \mu \mathrm{g})$.

The minimum inhibitory concentration (MIC) for cefotaxime and ceftazidime were determined using the agar-dilution method as recommended by the ACFMS for ESBL-carrying strains [9]. The cut-off values used for 
classification were: susceptible strains were defined as those having a MIC $<8 \mathrm{mg} / \mathrm{L}$ for cefotaxime, and a MIC $\leq 4 \mathrm{mg} / \mathrm{L}$ for ceftazidime; and resistant strains as those having a MIC $\geq 32 \mathrm{mg} / \mathrm{L}$ for cefotaxime and a MIC $\geq 8 \mathrm{mg} / \mathrm{L}$ for ceftazidime. E. coli ATCC 25922 was used as a control stain.

\section{Molecular characterization of ESBL-producing strains}

DNA was extracted using the Nucleospin tissue kit (Macherey Nagel, Hoerdt, France). Previously described polymerase chain reaction (PCR) methods were used to screen for plasmid-encoded $b l a_{C T X-M}, b l a_{\mathrm{tem}}$ and $b l a_{\mathrm{SHV}}$ genes [10-12]. Both $b l a_{\mathrm{CTX}-\mathrm{M}}, b l a_{\mathrm{SHV}}$ and $b l a_{\mathrm{TEM}}$ were then characterized by Direct DNA sequencing of the PCR products.

The nucleotide and deduced amino acid sequences were analyzed and compared with sequences available through the Internet on the National Center for Bio-technology Information web site (http://www.ncbi.nlm.nih.gov).

\section{Epidemiological data}

A standardized specific questionnaire was completed to collect demographic data. Risk factors for E. coli resistance to amoxicillin, third-generation cephalosporin (3GC) and ciprofloxacin were assessed from questions about: age, gender, chronic illness, hospitalization during the last year, UTI during the previous last 3 months, urinary catheterization during the previous year, antibiotic exposure during the last month, and hospital or family hospital occupation.

\section{Evolution of antibiotic resistance in E. coli from 2003}

To analyze the trends of resistance to antibiotics during the last 10 years, data were collected on the resistance of E. coli strains isolated from community-acquired UTIs in outpatients presenting at the emergency units of the hospitals of Basse-Terre and Pointe à Pitre and at the Pasteur Institute of Guadeloupe between 2003 and 2014. These data were added to that collected during the prospective study for 2013 and 2014.

\section{Data analysis}

Statistical analysis was performed using $\mathrm{R}$ software (reference: R Development Core Team. R: A Language and Environment for Statistical Computing [Internet]. Vienna, Austria: R Foundation for Statistical Computing; 2010. Available: http://www.R-project.org/).

We used logistic regression to estimate the relation between resistance to each antibiotic and the various covariates (age, gender, clinical symptoms). All covariates with a $\mathrm{p}$ value lower than 0.20 were included in the multivariable model. Multivariable, backward, step-bystep binomial negative regressions were used to take into account confounders, bias, and interactions linked to the dependent variable.

To compare annual resistance rates, we performed Poisson regression and chi2 tests. Statistical differences were considered significant for $p$-values $<0.05$.

\section{Results}

\section{Patients}

We collected a total of 1293 strains during the study period. Most (73.5 \%) were isolated from women (sex ratio 0.34). The median age of patients was 57.4 years (range 0 to 95 years). Sixteen patients carried significant numbers of two different strains. We obtained epidemiological data for 340 patients; pregnant women accounted for $10.6 \%$ of women interviewed, and $69 \%$ of patients had UTI symptoms.

\section{Bacterial strains and antibiotic susceptibility}

More than $86 \%$ of the isolates were Enterobacteriaceae: 736 E. coli (57.0 \%), 202 Klebsiella pneumoniae (15.5 \%), 56 Proteus mirabilis (4.3 \%), 54 Enterobacter spp. (4.2\%), 38 Citrobacter koseri (2.9\%), and 35 other Enterobacteriaceae (2.7 \%). Other Gram-negative bacteria (Pseudomonas spp. and Acinetobacter spp.) accounted for $0.6 \%$ of the isolates. Among the isolates, 170 were Gram-positive bacteria (13.1\%): Streptococcus agalactiae (4.3\%), Enterococcus faecalis (4.2 \%), and Staphylococcus saprophyticus $(2.3 \%)$.

Many of the E. coli isolates were susceptible to numerous drugs, but $42.1 \%$ of the strains were resistant to amoxicillin and ticarcillin.

A small proportion of strains were not susceptible to 3GC (3.1 \% E. coli and $12.2 \%$ other Enterobacteriaceae; Table 1). Most 3GC-resistant strains had a MIC greater than $64 \mathrm{mg} / \mathrm{L}$ for cefotaxim and ceftazidime (85 and $67.5 \%$, respectively). This resistance was mostly due to the presence of an ESBL $(n=39,85 \%): 24 K$. pneumoniae, $11 \mathrm{E}$. coli, 3 Enterobacter spp. and one $M$. morganii.

Resistance to cotrimoxazole and ciprofloxacin was 17.8 and $15.6 \%$, respectively.

Resistance rates to fosfomycin and nitrofurantoin were low among $E$. coli strains (1.6 and $1.2 \%$ respectively). These rates were higher for other Enterobacteriaceae: $17.9 \%$ for fosfomycin and $32.6 \%$ for nitrofurantoin.

Only a small proportion of Enterobacteriaceae strains were resistant to gentamicin $(6.4 \%)$ and amikacin (0.5 \%) (Table 1$)$. Only one strain (Morganella morganii) was resistant to imipenem.

Most 3GC-resistant strains had at least one coacquired resistance: $85 \%$ were resistant to ciprofloxacin, $67.5 \%$ to cotrimoxazole and $52.5 \%$ to gentamicin (Table 2). 
Table 1 Susceptibility of outpatients Enterobacteriaceae urinary isolates to various antimicrobial agents

\begin{tabular}{llll}
\hline & \multicolumn{2}{l}{ Number of isolates resistant to antibiotics (\%) } \\
\cline { 2 - 4 } & $\begin{array}{lll}\text { E. coli } \\
(n=733)\end{array}$ & $\begin{array}{l}\text { Other } \\
\text { Enterobacteriaceae } \\
(n=376)\end{array}$ & $\begin{array}{l}\text { All } \\
\text { Enterobacteriaceae } \\
(n=1109)\end{array}$ \\
\hline Amoxicillin & 42.1 & 88 & 57.6 \\
Co-amoxiclav & 18.6 & 32.7 & 23.4 \\
Ticarcillin & 38.9 & 75.8 & 51.4 \\
Cefalothin & 16.7 & 30 & 21.2 \\
Cefoxitin & 2.7 & 23.1 & 4.5 \\
Cefotaxim & 3.1 & 12.2 & 6.2 \\
Ceftazidim & 2.3 & 12.8 & 5.7 \\
Aztreonam & 1.9 & 11.7 & 7 \\
Imipenem & - & 6.7 & 2.3 \\
Cotrimoxazole & 18.6 & 16 & 17.8 \\
Amikacin & 0.4 & 0.5 & 0.5 \\
Gentamicin & 5.4 & 8.2 & 6.4 \\
Nalidixic acid & 19.7 & 21.3 & 20.2 \\
Ciprofloxacin & 13.8 & 19.4 & 15.6 \\
Fosfomycin & 1.6 & 17.9 & 7.1 \\
Nitrofurantoin & 1.2 & 32.6 & 13.7 \\
Tetracyclin & 25 & 32.7 & 27.6 \\
\hline
\end{tabular}

Determinants of antibiotic resistance in 3GC-R Enterobacteriaceae strains

The 39 ESBL producing strains are described in Table 2. Among them 38 expressed a CTX-M enzyme including 29 CTX-M15 and 7 CTX-M1. Additional $\beta$ lactamases were found in most of strains $(87.5 \%)$.

Risk factors for E. coli resistance to amoxicillin, third-generation cephalosporin and ciprofloxacin

Strains isolated from male patients had a significantly higher amoxicillin resistance rate than those isolated from female patients $(p=0.04)$. The ciprofloxacin resistance rate tended to increase with increasing age $(p<0.01)$ (Table 3).

Among 286 patients with an Enterobacteriaceae, 68 $(23.7 \%)$ declared to have received antibiotic treatment during the previous month and $72(25.2 \%)$ to have had a UTI during the three previous months. More Enterobacteriaceae strains isolated from patients who declared a UTI during the three previous months were resistant to amoxicillin $(p=0.02)$ and ciprofloxacin $(p<0.01)$ than those isolated from patients without a UTI during the three previous months. Moreover, urinary catheterization was associated with higher resistance rates for amoxicillin and cotrimoxazole $(p<0.01)$ (Table 3).

Evolution of antibiotic resistance in E. coli from 2003

Resistance rates for amoxicillin, cotrimoxazole and amikacin have been stable during the last 10 years. On the contrary, we found a significant $(p<0.01)$ increase in the

Table 2 Characteristics of the ESBLE ${ }^{a}$

\begin{tabular}{|c|c|c|c|c|c|c|c|}
\hline \multirow{2}{*}{$\begin{array}{l}\text { Species and } \\
\text { ESBL type }\end{array}$} & \multicolumn{3}{|c|}{ Additionnal $\beta$ lactamase } & \multicolumn{4}{|c|}{ Acquired co-resistance ${ }^{b}$} \\
\hline & non ESBL SHV & TEM1-like & OXA-1 like & $\mathrm{SXT}$ & GM & $\mathrm{CIP}$ & TE \\
\hline \multicolumn{8}{|l|}{ K. pneumoniae (24) } \\
\hline CTX M-15 (21) & 16 & 11 & 11 & 14 & 11 & 21 & 11 \\
\hline CTX M-1 (2) & 1 & 1 & 1 & 1 & 2 & 2 & 2 \\
\hline SHV-12 (1) & - & - & - & 1 & - & 2 & - \\
\hline \multicolumn{8}{|l|}{ E. coli $(11)$} \\
\hline CTX M-15 (5) & - & 2 & - & 3 & 2 & 3 & 3 \\
\hline CTX M-1 (4) & - & 3 & - & 4 & 2 & 1 & 3 \\
\hline CTX M-14 (1) & - & 1 & - & - & 1 & 1 & 1 \\
\hline CTX M-27 (1) & - & 1 & 1 & 1 & - & 1 & 1 \\
\hline \multicolumn{8}{|l|}{ E. cloacae (2) } \\
\hline CTX M-15 (2) & - & 2 & 2 & 2 & 1 & 2 & 1 \\
\hline \multicolumn{8}{|l|}{ E. aerogenes } \\
\hline CTX M-1 & - & - & - & - & - & - & - \\
\hline \multicolumn{8}{|l|}{ M. morganii } \\
\hline CTX M-15 & - & - & - & 1 & 1 & 1 & 1 \\
\hline
\end{tabular}

${ }^{a}$ Number of strains is indicated in parentheses when $>1$

${ }^{\mathrm{b}} \mathrm{S} X T$ cotrimoxazole, GM gentamicin, CIP ciprofloxacin, TE tetracyclin 
Table 3 Analysis of independent risk factors for E. coli resistance to amoxicillin, trimethoprim/sulfamethoxazole and ciprofloxacin

\begin{tabular}{|c|c|c|c|c|c|c|c|c|c|c|c|c|c|c|}
\hline \multirow[t]{2}{*}{ Risk factor } & \multirow[t]{2}{*}{ Number } & \multirow[t]{2}{*}{$\%$} & \multicolumn{4}{|l|}{ AMX } & \multicolumn{4}{|l|}{ SXT } & \multicolumn{3}{|l|}{ CIP } & \multirow[b]{2}{*}{$P$ value } \\
\hline & & & $\begin{array}{l}\text { Crude OR } \\
\text { [95\%] }\end{array}$ & $P$ value & $\begin{array}{l}\text { Ajusted OR } \\
\text { [95\%] }\end{array}$ & $P$ value & OR [95 \%] & $P$ value & $\begin{array}{l}\text { Ajusted OR } \\
{[950 \%]}\end{array}$ & $P$ value & OR [95 \%] & $P$ value & $\begin{array}{l}\text { Ajusted OR } \\
\text { [95\%] }\end{array}$ & \\
\hline Sex-Male & 124 & 19.9 & $1.5[1.1-2.3]$ & 0.04 & & & $1.4[0.8-2.2]$ & 0.21 & & & $1.6[0.9-2.7]$ & 0.09 & & \\
\hline \multicolumn{15}{|l|}{ Age category } \\
\hline less than 40 years & 168 & 26.9 & Ref & & & & Ref & & & & Ref & & & \\
\hline $40-59$ years & 141 & 23.7 & $0.9[0.5-1.4]$ & 0.55 & & & $1.1[0.6-2.0]$ & 0.81 & & & $2.7[1.1-6.9]$ & 0.03 & & \\
\hline $60-69$ years & 115 & 21.2 & $1.1[0.7-1.8]$ & 0.66 & & & $1.9[1.1-3.4]$ & 0.03 & & & 4.5 [1.9-10.9] & $<0.01$ & & \\
\hline 70 year and more & 176 & 28.2 & $1.2[0.7-1.8]$ & 0.45 & & & $1.9[1.1-3.3]$ & 0.03 & & & $4.8[2.1-11.3]$ & $<0.01$ & & \\
\hline $\begin{array}{l}\text { Presence of clinical } \\
\text { signs }\end{array}$ & 147 & 73.5 & $0.6[0.4-1]$ & 0.07 & $0.5[0.2-0.9]$ & 0.03 & $0.9[0.3-3.1]$ & 0.87 & & & $1.2[0.6-2.6]$ & 0.59 & & \\
\hline Chronic illness & 56 & 26.7 & $1.1[0.7-1.9]$ & 0.64 & & & $1.1[0.3-3.7]$ & 0.91 & & & $1.4[0.7-2.7]$ & 0.41 & & \\
\hline Prior (3 months) UTI & 52 & 24.8 & $1.8[1-3.2]$ & 0.04 & $2.3[1.1-4.9]$ & 0.02 & $3.1[1-10.1]$ & 0.05 & & & $5.4[2.7-11]$ & $<0.01$ & $5.1[2.5-10.3]$ & $<0.01$ \\
\hline $\begin{array}{l}\text { Prior ( } 12 \text { months) } \\
\text { hospitalization }\end{array}$ & 32 & 15.2 & $2.2[1.2-4.4]$ & 0.02 & & & $5.1[1.6-16.5]$ & $<0.01$ & & & $1.7[0.8-3.7]$ & 0.2 & & \\
\hline $\begin{array}{l}\text { Prior (6 months) } \\
\text { urinary catheter }\end{array}$ & 14 & 7 & $11.6[2.7-50.6]$ & $<0.01$ & 8.8 [1.9-40.8] & $<0.01$ & $10.1[2.5-40.4]$ & $<0.01$ & $11.1[2.4-51.6]$ & $<0.01$ & $2.1[0.7-5.7]$ & 0.16 & & \\
\hline $\begin{array}{l}\text { Prior ( } 6 \text { months) } \\
\text { antibiotic exposure }\end{array}$ & 14 & 21.4 & $1.4[0.8-2.4]$ & 0.26 & & & 3.8 [1.1-12.9] & 0.03 & 4 [0.9-18.9] & 0.07 & $2.4[1.2-4.9]$ & 0.02 & & \\
\hline
\end{tabular}

Only significant adjusted OR are presented

$O R$ odds ratio, UTI urinary tract infection

${ }^{*}$ Significant difference $(P<0.05)$ 
reported resistance to nalidixic acid, ciprofloxacin, cefalotin, and gentamycin (Table 4). The increase in the 3GC resistance rate was not significant as assessed by the Poisson regression test but was significant as evaluated by the Chi2 test. Until 2008, fewer than $1.0 \%$ of $E$. coli strains were resistant to $3 \mathrm{GC}$, but this proportion increased significantly between 2008 and $2009(p<0.01)$ and has been stable during the last 5 years (Table 4 ).

\section{Discussion}

As expected, E. coli was the most frequent strain isolated from urines in Guadeloupe (57.0\% of isolates), but nevertheless less frequent than in Europe and Canada (range from 61.0 to $87.5 \%$ ) [13-18]. K. pneumoniae was the second most frequent pathogen (15.5\%), even in pre-menopausal women, with a rate similar to those reported in Africa and Asia (ranging from 13.8 to $25.5 \%$ ) $[6,19-22]$. S. agalactiae was the most frequent Grampositive bacteria (4.3\%), whereas generally reported rates are less than $3 \%$. The differences in relative prevalence may be due to environmental and/or host genetic factors, or the virulence of the bacterial pathogens. Of note, the prevalence of diabetes is high $(8.2 \%)$ in Guadeloupe [23] and UTIs due to K. pneumoniae and $S$. agalactiae have been reported to be two to three times more frequent among patients with diabetes than those without [24].

As previously described, S. saprophyticus was isolated more frequently from women under 35 years of age than men or older women [25].

Overall, resistance rates were similar to those observed in developed countries including mainland France. Indeed, we found an amoxicillin-resistance rate of $42.1 \%$ for E. coli, similar to the rate of $43.4 \%$ reported for North America [26] and slightly lower than the rate of $48.3 \%$ reported for Europe [27]. This contrasts with the reported situation in African and developing Asian countries where resistance rates may be as high as $80 \%[6,7,28,29]$.
Moreover, resistance to $3 \mathrm{GC}$ was low, and although this rate increased significantly between 2008 and 2009, it remains below $4 \%$ for E. coli strains and $7 \%$ for all Enterobacteriaceae. Guadeloupe should be considered to be a low prevalence ESBL-producing Enterobacteriaceae territory as are the European and North American countries $[5,15,27,30]$. In our study, bla $a_{\text {CTX-M15 }}$ was detected in most of the ESBL-producing strains (74.3 \%), highlighting the shift during the 2000s from ESBL $b l a_{\mathrm{TEM}} / b l a_{\mathrm{SHV}}$ to ESBL group $1 b l a_{\mathrm{CTX}-\mathrm{M}}$, and in particular to $b l a_{\text {CTX-M15. This is in accordance with other }}$ epidemiological studies of ESBL-producing Enterobacteriaceae [31]. Most ESBL-producing strains (97.5\%) were resistant to other antibiotics in keeping with the ARESC and ECO-SENS II studies [5, 27]. Surprisingly, most ESBL-producing strains isolated in our study were $K$. pneumoniae, whereas in the community, E. coli strains with CTX-M enzymes usually predominate [32] because of the spread of clonal multidrug-resistant $E$. coli strains such as clone O25b-ST131 [33]. The prevalence of $K$. pneumoniae in our study can be explained not only by the high proportion of $K$. pneumoniae strains among uropathogens, but also by the spread of successful clones as described in Africa and Asia [34].

We did not isolate any carbapenemase-producing strains, although these strains have been observed in the community, even in low prevalence countries such as England [15] where their presence is often related to travel in Asia where these strains are endemic [35]. In Guadeloupe, Enterobacteriaceae carbapenemase-producing strains have just begun to emerge in hospital settings with the first description of an NDM-1-producing $K$. pneumoniae in 2014 [36], and more recently, of an OXA-48-producing E. coli [37].

Ciprofloxacin resistance remains moderate (15.6\%) compared to rates observed in Asia which can be as high as $75 \%$ [19]. Nevertheless, we found that this rate has increased significantly during the last 10 years as described for other countries [6, 15, 26, 38]. Although

Table 4 Trends of resistance rates to various antimicrobial agents of E. coli between 2003 and 2014

\begin{tabular}{llllllllllllll}
\hline Year & 2003 & 2004 & 2005 & 2006 & 2007 & 2008 & 2009 & 2010 & 2011 & 2012 & 2013 & 2014 & $P$ value \\
n E.coli & 198 & 300 & 338 & 437 & 384 & 399 & 606 & 763 & 854 & 766 & 1019 & 950 & \\
\hline Amoxicillin & 43 & 46.6 & 43 & 42.3 & 43.2 & 44.1 & 39.7 & 37.7 & 45 & 44.2 & 41.4 & 42.9 & NS \\
Cefalotin & 8 & 6.3 & 7.8 & 7.3 & 5.5 & 6.2 & 15 & 14 & 16.6 & 17.6 & 17 & 20.4 & $<0.01^{*}$ \\
Cefotaxime & 0 & 0.7 & 0.3 & 0 & 0.9 & 0.2 & 1.8 & 2.5 & 2.7 & 3 & 2.6 & 2.3 & $<0.01^{* *}$ \\
Amikacin & 0.5 & 0.0 & 0.0 & 0.5 & 0.6 & 0.2 & 0.2 & 1 & 0.7 & 0.3 & 0.3 & 0.3 & NS \\
Gentamicin & 1 & 3.3 & 4.4 & 2.3 & 2.6 & 4.2 & 3.6 & 3.9 & 5.6 & 5.2 & 3.4 & 4.6 & $<0.01^{*}$ \\
Nalidixic acid & 5.5 & 11 & UD & UD & UD & 13.4 & 15 & 13.1 & 13.7 & 17.2 & 16.2 & 20.8 & $<0.01^{*}$ \\
Ciprofloxacin & 4 & 5.3 & 6.8 & 8.5 & 9.6 & 8.5 & 11.4 & 8.2 & 10.9 & 9.9 & 9.9 & 12.3 & $<0.01^{*}$ \\
Cotrimoxazole & 18.7 & 23 & 21.6 & 22.4 & 23.2 & 23.3 & 20.9 & 19 & 20.5 & 19.4 & 18.6 & 18 & NS \\
\hline
\end{tabular}


we were not able to obtain retrospective data on fluoroquinolone consumption in Guadeloupe, increasing rates of ciprofloxacin-resistant strains suggest the inappropriate use of fluroquinolones in outpatients. Among the 48 patients reporting antibiotic consumption during the month prior to the infection, 15 had consumed a fluoroquinolone and among 24 patients that also reported a previous UTI, 12 received a fluoroquinolones whereas only one was given fosfomycin. Indeed, ciprofloxacin resistance in $E$. coli has been linked with ciprofloxacin consumption in the same month as the infection and the month before [39]. The rate of ciprofloxacin resistance tended to increase with age as has been described for mainland France and Canada [16, 40] Antimicrobial susceptibility testing of uropathogens is known to overestimate rates of resistance because antibiograms are performed mostly if empirical treatment fails, or if patients have underlying factors [41]. Nevertheless, the trends remain valid.

Consistent with previous reports $[28,42]$ we observed that prior UTI (likely to be associated with prior antibiotic treatment) was associated with higher amoxicillin and ciprofloxacin resistance rates. This suggests the abusive use of these antibiotics for the treatment of community acquired infections. Surprisingly, a previous antibiotic treatment was not associated with such a risk. Since the use of antibiotics for which the resistance rate exceeds $10-20 \%$ is associated with an increased risk of treatment failure and the selection of resistant strains [43], ciprofloxacin should be administered only if compatible with the antimicrobial resistance pattern of the strain.

\section{Conclusions}

Although a few patients may have been infected by hospital-acquired strains, this is the first description of susceptibility patterns of urinary bacterial strains isolated from outpatients in Guadeloupe.

The antibiotic resistance rates among urinary bacteria isolates from outpatients in Guadeloupe are similar to those of North America and Europe. Nevertheless, this study highlights the need for general practitioners in Guadeloupe to be better informed so that they are encouraged to prescribe fosfomycin-trometamol for the treatment of UTI to reduce the risk of increasing resistance rates to fluoroquinolones.

\section{Abbreviations \\ UTI, urinary tract infection; SPFIL, The French Language Infectious Disease Society; ESBL, Extended Spectrum beta lactamase; MIC, minimum inhibitory concentration; PCR, polymerase chain reaction; $3 G C$, third generation cephalosporin}

Acknowledgements

We thank all study participants.
The laboratory working group includes: Clément Bourgoin ${ }^{1}$, Farid Saheb ${ }^{1}$, Guy-Joseph Theodore', Emmanuelle Bourgoin', Frédéric Leroy', William Laurent', Arnaud Lethuillier ${ }^{1}$, Patricia Tamby ${ }^{1}$, Petra Kassab ${ }^{1}$, Anne-Christine Becker ${ }^{1}$, Pierre Marie ${ }^{1}$, Sandrine Hippomène ${ }^{2}$, Olivier Menuteau², Marie-Line Péan², Sylvaine Bastian ${ }^{3}$, Edith Malpote ${ }^{3}$, Didier Mattera ${ }^{4}$

${ }^{1}$ Laboratoire Biopole Antilles

²aboratoire Synergibio

${ }^{3}$ Laboratoire de Microbiologie, Centre Hospitalo-Universitaire, Les Abymes

${ }^{4}$ Laboratoire de Biologie Clinique, Centre Hospitalier de Basse-Terre, Basse-Terre, Guadeloupe

\section{Funding}

This work was financed by grants from the Institut Pasteur International Network, ACIP A13_2011 and by grant FEDER FED-1-1.4 32932 from the European Union.

\section{Availability of data and materials}

Data supporting the findings is contained within the manuscript.

\section{Author's contributions}

SG designed the study, analyzed data and wrote the manuscript, JM, CD and SS collected bacterial strains and epidemiological data, performed antimicrobial susceptibility testing and molecular characterization of ESBLproducing strains, MF performed molecular characterization of ESBLproducing strains, DH collected bacterial strains, epidemiological data and retrospective data on the resistance of $E$. coli strains and critically revised the manuscript, VR performed data analysis and critically revised the manuscript, ChD designed the study and critically revised the manuscript, SB collected retrospective data on the resistance of $E$. coli strains and critically revised the manuscript, AT designed the study and critically revised the manuscript. All authors read and approved the final manuscript.

\section{Competing interests}

The authors declare that they have no competing interests.

\section{Consent for publication}

Not applicable.

\section{Ethics approval and consent to participate}

The study protocols were approved by the French Advisory Committee on Information Processing in Material Research in the Field of Health (CCTIRS 12-220). Written informed consent to participate in the study was obtained from all patients.

\section{Author details}

'Unité Environnement Santé, Institut Pasteur de Guadeloupe, Les Abymes, Guadeloupe, France. 'Laboratoire de Biologie Clinique, Centre Hospitalier de Basse-Terre, Basse-Terre, Guadeloupe, France. ${ }^{3}$ Faculté de Médecine, Université des Antilles, Pointe-à-Pitre, Guadeloupe, France. ${ }^{4}$ Laboratoire de Microbiologie Clinique et Environnementale, Centre Hospitalo-Universitaire de Pointe-à-Pitre/Abymes, Pointe-à-Pitre, Guadeloupe, France. ${ }^{5}$ Institut Pasteur de Nouvelle-Calédonie, Nouméa, Nouvelle-Calédonie, France. ${ }^{6}$ Institut Armand Frappier, Laval, Canada.

Received: 5 January 2016 Accepted: 15 June 2016

Published online: 24 June 2016

References

1. Flores-Mireles AL, Walker JN, Caparon M, Hultgren SJ. Urinary tract infections: epidemiology, mechanisms of infection and treatment options. Nat Rev Microbiol. 2015;13:269-84.

2. Bishop MC. Uncomplicated Urinary Tract Infection. EAU Updat Ser. 2004;2:143-50.

3. Rogers BA, Sidjabat HE, Paterson DL. Escherichia coli O25b-ST131: a pandemic, multiresistant, community-associated strain. J Antimicrob Chemother. 2011;66:1-14.

4. Kahlmeter G, Menday P. Cross-resistance and associated resistance in 2478 Escherichia coli isolates from the Pan-European ECO.SENS Project surveying the antimicrobial susceptibility of pathogens from uncomplicated urinary tract infections. J Antimicrob Chemother. 2003;52:128-31. 
5. Kahlmeter G, Poulsen HO. Antimicrobial susceptibility of Escherichia coli from community-acquired urinary tract infections in Europe: The ECO SENS study revisited. Int J Antimicrob Agents. 2012;39:45-51.

6. Bercion R, Mossoro-Kpinde D, Manirakiza A, Le Faou A. Increasing prevalence of antimicrobial resistance among Enterobacteriaceae uropathogens in Bangui, Central African Republic. J Infect Dev Ctries. 2009:3:187-90.

7. Sire $\mathbf{J M}$, et al. Antimicrobial resistance in outpatient Escherichia coli urinary isolates in Dakar, Senegal. J Infect Dev Ctries. 2007;1:263-8.

8. SPILF 2014 Mise au point Diagnostic et Antibiothérapie des infections Urinaires Bactériennes Communautaires de l'Adulte. Splif. 2014. http://www. infectiologie.com/UserFiles/File/medias/Recos/2014-infections_urinaireslong.pdf.

9. CA-SFM. Comite de l'Antibiogramme de la Societe Francaise de Microbiologie: Recommandations. 2013. Edition de janvier 2013.

10. Saladin M, et al. Diversity of CTX-M beta-lactamases and their promoter regions from Enterobacteriaceae isolated in three Parisian hospitals. FEMS Microbiol Lett. 2002:209:161-8.

11. Arlet G. Rouveau, M. \& Philippon, a. Substitution of alanine for aspartate at position 179 in the SHV-6 extended-spectrum beta-lactamase. FEMS Microbiol Lett. 1997;152:163-7.

12. Eckert $C$, et al. Dissemination of CTX-M-Type $\beta$-Lactamases among Clinical Isolates of Enterobacteriaceae in Paris, France. Antimicrob Agents Chemother. 2004:48:1249-55.

13. Hryniewicz K, et al. Antibiotic susceptibility of bacterial strains isolated from urinary tract infections in Poland. J Antimicrob Chemother. 2001;47:773-80.

14. Bruyère $F$, Vidoni $M$, Péan $Y$, Ruimy JA, Elfassi R. Analyse microbiologique de plus de 600 infections urinaires fébriles prises en charge dans un réseau de soin. Progrès en Urol. 2013;23:890-8.

15. Ironmonger $D$, et al. Surveillance of antibiotic susceptibility of urinary tract pathogens for a population of 5.6 million over 4 years. J Antimicrob Chemother. 2015;70:1744-50.

16. Laupland KB, Ross T, Pitout JDD, Church DL, Gregson DB. Community-onset urinary tract infections: A population-based assessment. Infection. 2007:35:150-3.

17. Magliano E, et al. Gender and age-dependent etiology of community-acquired urinary tract infections. ScientificWorldJournal. 2012;2012:349597.

18. Maraki S, Mantadakis E, Michailidis L, Samonis G. Changing antibiotic susceptibilities of community-acquired uropathogens in Greece, 2005-2010. J Microbiol Immunol Infect. 2013;46:202-9.

19. Lu PL, et al. Epidemiology and antimicrobial susceptibility profiles of Gramnegative bacteria causing urinary tract infections in the Asia-Pacific region: 2009-2010 results from the Study for Monitoring Antimicrobial Resistance Trends (SMART). Int J Antimicrob Agents. 2012;40:S37-43.

20. Hanley J, Branford I, Gugnan HC, Wilkinson C. U. T. urinary bacterial pathognes in St. Kitts.pdf. West Indies Med J. 2009:58:670.

21. Kothari A, Sagar $V$. Antibiotic resistance in pathogens causing communityacquired urinary tract infections in India: a multicenter study. J Infect Dev Ctries. 2008;2:354-8.

22. Akoachere J-FTK, Yvonne S, Akum NH, Seraphine EN. Etiologic profile and antimicrobial susceptibility of community-acquired urinary tract infection in two Cameroonian towns. BMC Res Notes. 2012;5:219.

23. Fosse-Edorh S. Journée modiale du diabète. Beh. 2014;30-31:491-529.

24. Ronald A. The etiology of urinary tract infection: Traditional and emerging pathogens. Dis Mon. 2003:49:71-82.

25. Raz R, Colodner R, Kunin CM. Who are you - Staphylococcus saprophyticus? Clin Infect Dis. 2005;40:896-8.

26. Sanchez GV, Master RN, Karlowsky JA, Bordon JM. In vitro antimicrobial resistance of urinary Escherichia coli isolates among U.S. outpatients from 2000 to 2010. Antimicrob Agents Chemother. 2012;56:2181-3.

27. Schito GC, et al. The ARESC study: an international survey on the antimicrobial resistance of pathogens involved in uncomplicated urinary tract infections. Int J Antimicrob Agents. 2009;34:407-13.

28. Randrianirina $F$, et al. Antimicrobial resistance among uropathogens that cause community-acquired urinary tract infections in Antananarivo, Madagascar. J Antimicrob Chemother. 2007;59:309-12.

29. Ma KL, Wang CX. Analysis of the spectrum and antibiotic resistance of uropathogens in vitro: Results based on a retrospective study from a tertiary hospital. Am J Infect Control. 2013:41:601-6.

30. Laupland KB, Church DL, Vidakovich J, Mucenski M, Pitout JDD. Communityonset extended-spectrum beta-lactamase (ESBL) producing Escherichia coli: importance of international travel. J Infect. 2008;57:441-8.
31. Arpin C, et al. Nationwide survey of extended-spectrum \{beta\}-lactamaseproducing Enterobacteriaceae in the French community setting. J Antimicrob Chemother. 2009;63:1205-14.

32. Pitout JDD, Laupland KB. Extended-spectrum beta-lactamase-producing Enterobacteriaceae: an emerging public-health concern. Lancet Infect Dis. 2008:8:159-66

33. Smith SP, Manges AR, Riley LW. Temporal changes in the prevalence of community-acquired antimicrobial-resistant urinary tract infection affected by Escherichia coli clonal group composition. Clin Infect Dis. 2008;46:689-95.

34. Breurec $S$, et al. Klebsiella pneumoniae resistant to third-generation cephalosporins in five African and two Vietnamese major towns: Multiclonal population structure with two major international clonal groups, CG15 and CG258. Clin Microbiol Infect. 2013;19:349-55.

35. Kumarasamy KK, et al. Emergence of a new antibiotic resistance mechanism in India, Pakistan, and the UK: A molecular, biological, and epidemiological study. Lancet Infect Dis. 2010;10:597-602.

36. Bastian $\mathrm{S}$, et al. First case of NDM-1 producing Klebsiella pneumoniae in Caribbean islands. Int J Infect Dis. 2015;34:e53-4.

37. Breurec $S$, et al. Emergence of OXA-48-producing Escherichia coli in the Caribbean islands. J Glob Antimicrob Resist. 2015:3:217-8.

38. Andrade SS, et al. Increased resistance to first-line agents among bacterial pathogens isolated from urinary tract infections in Latin America: Time for local guidelines? Mem Inst Oswaldo Cruz. 2006;101:741-8.

39. Vernaz $\mathrm{N}$, et al. Modelling the impact of antibiotic use on antibiotic-resistant Escherichia coli using population-based data from a large hospital and its surrounding community. J Antimicrob Chemother. 2011;66:928-35.

40. Grignon $\mathrm{O}$, et al. Escherichia coli antibiotic resistance in emergency departments. Do local resistance rates matter? Eur J Clin Microbiol Infect Dis. 2014;34:571-7.

41. Heginbothom $M L$, et al. Laboratory testing policies and their effects on routine surveillance of community antimicrobial resistance. J Antimicrob Chemother. 2004;53:1010-7.

42. Dromigny JA, Nabeth $P$, Juergens-Behr A, Perrier-Gros-Claude JD. Risk factors for antibiotic-resistant Escherichia coli isolated from communityacquired urinary tract infections in Dakar, Senegal. J Antimicrob Chemother 2005;56:236-9.

43. Dalhoff A. Global fluoroquinolone resistance epidemiology and implictions for clinical use. Interdiscip Perspect Infect Dis. 2012;2012:976273.

\section{Submit your next manuscript to BioMed Central and we will help you at every step:}

- We accept pre-submission inquiries

- Our selector tool helps you to find the most relevant journal

- We provide round the clock customer support

- Convenient online submission

- Thorough peer review

- Inclusion in PubMed and all major indexing services

- Maximum visibility for your research

Submit your manuscript at www.biomedcentral.com/submit
) Biomed Central 